\title{
Optimization and single-stage centrifugal contactor experiments with the novel hydrophilic complexant PyTri-Diol for the $i$ - SANEX process
}

Eros Mossini $^{1 *}$, Elena Macerata ${ }^{1}$, Andreas Wilden $^{2}$, Peter Kaufholz $^{2}$, Giuseppe Modolo ${ }^{2}$, Nicolò Iotti ${ }^{3}$, Alessandro Casnati ${ }^{3}$, Andreas Geist ${ }^{4}$, Mario Mariani ${ }^{1}$

${ }^{1}$ Politecnico di Milano, Energy Department - Nuclear Engineering Section, Via La Masa 34, 20156

Milano, Italy, Fax: +39.02.23996369; Tel: +39.02.23996395

${ }^{2}$ Forschungszentrum Jülich GmbH, Institut für Energie und Klimaforschung - Nukleare Entsorgung und Reaktorsicherheit (IEK-6), 52428 Jülich, Germany

${ }^{3}$ Department of Chemistry, Life Sciences and Environmental Sustainability, Università di Parma, Parco Area delle Scienze 17/a, 43124 Parma, Italy

${ }^{4}$ Karlsruhe Institute of Technology (KIT), Institute for Nuclear Waste Disposal (INE), 76021

Karlsruhe, Germany

*Corresponding author e-mail: eros.mossini@polimi.it

KEYWORDS: partitioning, $i$-SANEX, PyTri ligand, TODGA, single-stage centrifugal contactor 


\begin{abstract}
The applicability of 2,6-bis[1-(propan-1-ol)-1,2,3-triazol-4-yl)]pyridine (PyTri-Diol) in $i$ SANEX process as water-soluble complexing agent was studied. Preliminary batch experiments were aimed at identifying the optimal formulation of the PyTri-Diol solution and at preparing the ground for single-stage centrifugal contactor experiments. A TODGA-based solvent loaded using a spiked synthetic PUREX raffinate and the optimized PyTri-Diol aqueous phase were contacted in a single-stage annular centrifugal contactor setup with three different flow-rate conditions. No hydrodynamic problems were encountered and promising minor actinides separation from other cations was achieved with satisfactory kinetics and stage efficiency. The flow-sheet of a TODGA-PyTri-Diol based $i$-SANEX process was designed exploiting batch and single-stage data, promoting the CHON compliant PyTri-Diol as excellent alternative to the formerly used $\mathrm{SO}_{3}-\mathrm{Ph}-\mathrm{BTP}$.
\end{abstract}




\section{INTRODUCTION}

Nuclear energy could play a role in the development of a sustainable energy supply paying heed to climate and environmental safeguard. However, management of spent nuclear fuel (SNF) remains one of the major concerns for its public acceptance [1]. Up to December 2015, 266,000 tons of heavy metals $\left(t_{\mathrm{HM}}\right) \mathrm{SNF}$ have been accumulated globally at a rate of approximately 7,000 $t_{\mathrm{HM}} \mathrm{SNF}$ per year [2]. The relief of this undue radioactive and radiotoxic burden to future generations can be pursued by a closed nuclear fuel cycle [3]. Up to now, safe, efficient and cost-effective hydrometallurgical processes, above all the Plutonium and Uranium Reduction EXtraction process (PUREX), have been successfully developed to recover uranium and plutonium isotopes [4], i.e. about $95 \%$ of the SNF inventory after 40 $\mathrm{GWd} / \mathrm{t}$ burn up [5]. Mono-recycling of $\mathrm{U}$ and $\mathrm{Pu}$ allows saving at least $15 \%$ of natural uranium resources, thus reducing the front-end activities and improving the already competitive nuclear energy environmental footprint [6]. Moreover, a significant reduction of the amount of long-lived High Level Waste is achieved, thus allowing a relief of the repository footprint both in terms of waste disposal volume and surface area due to the lower waste heat-load $[7,8]$. Furthermore, multi-recycling of U, Pu and minor actinides (MA: Np, Am, Cm) in Fast Neutron Reactors would allow to produce electricity from existing SNF stockpiles for several thousands of years, thus improving nuclear sustainability along with its environmental footprint $[6,9]$. Neptunium can be recovered along with $\mathrm{U}$ and $\mathrm{Pu}$ in advanced PUREX processes [10]. The other trivalent MA can be separated from Highly Active Raffinate (HAR) and can be recycled in generation IV nuclear systems according to the Partitioning and Transmutation (P\&T) strategy [11]. Due to their high neutron-capture crosssection, the trivalent lanthanides ( $\mathrm{Ln})$ must be removed to allow efficient MA transmutation [12]. Unfortunately, the unfavorable mass ratio along with the similar chemical behavior of trivalent MA and Ln are major difficulties to be dealt with in the development of MA 
separation processes [13]. Nevertheless, the separation of trivalent MA from the Ln becomes possible with ligands containing soft electron-donor atoms $[14,15,16,17,18]$. The $1,2,4$ triazine bearing ligands, in particular 2,6-bis(1,2,4-triazin-3-yl)pyridines (BTP), 6,6'bis(1,2,4-triazin-3-yl)-2,2'-bipyridines (BTBP) and 2,9-bis(1,2,4-triazin-3-yl)-1,10phenanthroline (BTPhen), have proved to be promising to achieve the MA(III)/Ln(III) separation [19].

Due to the difficult separation of trivalent MA and lanthanides a two-step approach had been followed. Several hydrometallurgical partitioning approaches have been developed for the simultaneous removal of $4 \mathrm{f}$ and $5 \mathrm{f}$ elements from the PUREX raffinate, such as the DIAMide EXtraction (DIAMEX) process using malonamides or the TRansUranic EXtraction (TRUEX) or the TRialkyl Phosphine Oxide (TRPO) processes by means of phosphine oxide extractants [20,21]. Afterwards, as prompted by the Selective ActiNide EXtraction (SANEX) process, a separation of the trivalent MA from the Ln was achieved by the selective extraction of MA from the DIAMEX raffinate using a lipophilic N-donor extractant [22]. In the U.S., the Trivalent Actinide Lanthanide Separation with Phosphorus-reagent Extraction from Aqueous Komplexes (TALSPEAK) process has been designed to enable the selective extraction of Ln supported by a selective retention of MA in the aqueous phase [23]. Recently, an Advanced TALSPEAK process has been developed and demonstrated at the laboratory scale [24,25]. Although demonstrated at the pilot-scale, the industrial implementation of the TALSPEAK process has been hindered by its complexity. As valid alternatives, the American reverse TALSPEAK and the Japanese Solvent Extraction for Trivalent f-elements Intra-group separation in CMPO-complexant System (SETFICS) processes envisage the MA selective stripping by an aqueous hydrophilic complexant [26,27]. Likewise, exploiting the same concept of the reverse TALSPEAK, the Actinide Lanthanide SEParation (ALSEP) process has been developed to improve the TRUEX-TALSPEAK combined approach [28]. 
Within the previous joint research projects funded by the European Commission, single cycle hydrometallurgical processes have been proposed for the direct separation of trivalent MA from the PUREX raffinate $[13,29]$. Among them, the innovative SANEX ( $i$-SANEX) process entails the preliminary MA(III) and $\mathrm{Ln}(\mathrm{III})$ co-extraction from other fission and corrosion products by a non-selective lipophilic ligand, e.g. N,N,N',N' tetraoctyl diglycolamide (TODGA) [30], see Figure 1 (Left). This extractant has been studied by batch and multi-stage centrifugal contactor battery tests, also in presence of a genuine fuel raffinate solution [31,32,33]. Afterwards, the MA(III) were back-extracted (stripped) from the organic phase using a selective hydrophilic complexing agent. Whereas TODGA proved to satisfy the technological requirements, the main challenge lies in the design of a water-soluble complexant fulfilling additional requirements: i) MA(III)/Ln(III) selectivity; ii) reversibility of MA(III) retention; iii) fast complexation kinetics; iv) no hydrodynamic issues; v) stability towards hydrolysis and radiolysis [13,34]. Furthermore, an optimal complexant should contain only $\mathrm{C}, \mathrm{H}, \mathrm{O}$ and $\mathrm{N}$ atoms in order to be fully incinerable without bequeathing secondary solid wastes [35]. Several promising hydrophilic complexants have been developed although they do not fully match all requirements [36]. The sulfophenyl-BTP $(2,6-$ bis(5,6-di(sulfophenyl)-1,2,4-triazin-3-yl)pyridine, $\mathrm{SO}_{3}$-Ph-BTP) [37] molecule has been studied under the perspective of fundamental properties [38] as well as for process development in single and multi-stage centrifugal contactor batteries [39,40,41]. Its main disadvantage is the presence of sulfophenyl groups that hinder complete decomposition to gaseous products. Recently, since an alternative to $\mathrm{SO}_{3}-\mathrm{Ph}-\mathrm{BTP}$ with similar selectivity but containing just $\mathrm{C}, \mathrm{H}, \mathrm{O}, \mathrm{N}$ atoms is extremely desirable, 2,6-bis [1-(propan-1-ol)-1,2,3triazol-4-yl)]pyridine (PyTri Diol, see Figure 1, Right) has been proposed as a promising hydrophilic $i$-SANEX complexing agent [42]. Its tridentate $\mathrm{N}$ donor chelating unit has been conceived in order to enhance MA(III)/Ln(III) selectivity and hydrophilicity was achieved by 
functionalization with alkyl chains bearing hydroxyl groups. The fulfilment of the above described requirements has already been demonstrated, in particular concerning MA(III)/Ln(III) selectivity and stability towards radiolysis by means of batch solvent extraction, spectroscopic complexometric titration and analytical chemistry experiments $[42,43]$.

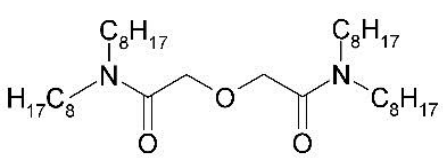

TODGA

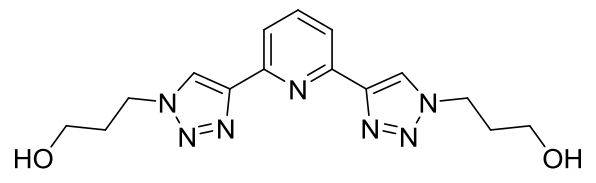

PyTri-Diol

Figure 1. Molecular structures of TODGA (Left) and PyTri-Diol (Right).

The purpose of this work is to assess the applicability of the TODGA-PyTri-Diol system in a counter current process setup. With this regard, preliminary batch solvent extraction tests were performed in order to confirm the working conditions. Afterwards, single-stage centrifugal contactor experiments were carried out. Three flow-rates were tested so as to evaluate the transfer kinetics and the single-stage efficiency. 


\section{EXPERIMENTAL}

\section{General methods and chemicals}

TODGA was obtained from TechnoComm Ltd. (Wellbrae, Falkland, Scotland) and used without further purification. PyTri-Diol was synthesized by University of Parma according to the procedure described elsewhere [42]. All other chemicals were purchased from commercial vendors and used as received. Aqueous solutions were prepared using ultrapure water (ELGA Purelab Ultra, Celle, Germany; $18.2 \mathrm{M} \Omega \cdot \mathrm{cm})$. The radiotracers ${ }^{241} \mathrm{Am}(\mathrm{III})$, ${ }^{244} \mathrm{Cm}$ (III) and ${ }^{152} \mathrm{Eu}$ (III) were purchased from Isotopendienst M. Blaseg GmbH, Waldburg, Germany, Oak Ridge National Laboratory, Oak Ridge, USA, and Eckert \& Ziegler Nuclitec GmbH, Braunschweig, Germany, respectively.

\section{Batch extraction experiments}

Unless otherwise specified, equal volumes of aqueous and organic phases were used in the experiments. The organic phase consisted of $0.2 \mathrm{~mol} / \mathrm{L}$ TODGA dissolved in hydrogenated tetrapropene (TPH) with 5 vol.-\% 1-octanol. Two different aqueous feeds were used for the tests: Feed 1 contained $10^{-5} \mathrm{~mol} / \mathrm{L}$ of each lanthanide (La - Lu, w/o Pm), the composition of Feed 2 aims at the simulation of a PUREX raffinate solution. The composition of Feed 2 is reported in Table 1 [44]. Both aqueous solutions were spiked with about $10 \mathrm{kBq}$ of ${ }^{241} \mathrm{Am}$ (III) and ${ }^{152} \mathrm{Eu}(\mathrm{III})$ each. Preliminary solvent extraction experiments were performed in order to optimize the composition of the PyTri-Diol based aqueous solutions by directly dissolving weighted amounts of ligand in Feed 1 and contacting it with a fresh TODGA solution. The content of PyTri-Diol and $\mathrm{HNO}_{3}$ in the aqueous phase was properly adjusted in order to investigate the effects of different acidity and complexant concentration on the system performance. In order to verify the viability of the complexing agent in a more representative condition, several experiments were carried out with a TODGA phase previously loaded by 
batch contacting it with Feed 2 and scrubbing with $0.5 \mathrm{~mol} / \mathrm{L} \mathrm{HNO}_{3}$ to back-extract undesired $\mathrm{Sr}$ and co-extracted nitric acid. According to previous work, $0.05 \mathrm{~mol} / \mathrm{L}$ trans 1,2diaminocyclohexane- $N, N, N^{\prime}, N^{\prime}$-tetraacetic acid (CDTA) has been added to Feed 2 in order to hinder the extraction of $\mathrm{Zr}$ and Pd by TODGA [45].

Table 1. Composition of synthetic PUREX raffinate solution (Feed 2), $3.1 \mathrm{~mol} / \mathrm{L}$ initial $\mathrm{HNO}_{3}$

\begin{tabular}{cccccc}
\hline Element & $\begin{array}{c}\text { Concentration } \\
{[\mathrm{mg} / \mathrm{L}]}\end{array}$ & Element & $\begin{array}{c}\text { Concentration } \\
{[\mathrm{mg} / \mathrm{L}]}\end{array}$ & Element & $\begin{array}{c}\text { Concentration } \\
{[\mathrm{mg} / \mathrm{L}]}\end{array}$ \\
\hline $\mathrm{Se}$ & 35 & $\mathrm{Zr}$ & 833 & $\mathrm{Cs}$ & 465 \\
$\mathrm{Fe}$ & 1900 & $\mathrm{Mo}$ & 620 & $\mathrm{Ba}$ & 255 \\
$\mathrm{Na}$ & 1480 & $\mathrm{Ru}$ & 351 & $\mathrm{La}$ & 237 \\
$\mathrm{Al}$ & 3 & $\mathrm{Rh}$ & 69 & $\mathrm{Ce}$ & 532 \\
$\mathrm{Cr}$ & 94 & $\mathrm{Pd}$ & 96 & $\mathrm{Pr}$ & 210 \\
$\mathrm{Ni}$ & 45 & $\mathrm{Ag}$ & 12 & $\mathrm{Nd}$ & 679 \\
$\mathrm{Cu}$ & 17 & $\mathrm{Cd}$ & 19 & $\mathrm{Sm}$ & 138 \\
$\mathrm{Rb}$ & 68 & $\mathrm{Sn}$ & 0.1 & $\mathrm{Eu}$ & 33 \\
$\mathrm{Sr}$ & 161 & $\mathrm{Sb}$ & 5 & $\mathrm{Gd}$ & 32 \\
$\mathrm{Y}$ & 86 & $\mathrm{Te}$ & 99 & & \\
\hline
\end{tabular}

Extraction experiments were performed by contacting $500 \mu \mathrm{L}$ of both phases in $2 \mathrm{~mL}$ glass vials. The mixing was ensured by a horizontal shaker at $2500 \mathrm{rpm}$ for 60 minutes, with the temperature fixed at $25^{\circ} \mathrm{C}$. As outlined from preliminary experiments, this mixing time turned out to be far enough to reach equilibrium [42]. After phase separation, aliquots of both phases $(300 \mu \mathrm{L})$ were collected for the $\gamma$-measurement using a High Purity Germanium detector (EG \& G Ortec, Munich, Germany). The $\gamma$-lines at $59.5 \mathrm{keV}$ and $121.8 \mathrm{keV}$ were exploited for the quantification of ${ }^{241} \mathrm{Am}(\mathrm{III})$ and ${ }^{152} \mathrm{Eu}(\mathrm{III})$, respectively. Additional aliquots of both phases $(100 \mu \mathrm{L})$ were collected for Inductively Coupled Plasma - Mass Spectrometry (ICP-MS; Elan 6100 DRC, Perkin Elmer Sciex, Rodgau-Jügesheim, Germany). Aqueous and organic phases were diluted to adequate cation concentration using $1 \% \mathrm{HNO}_{3}$ (approximately $0.16 \mathrm{~mol} / \mathrm{L}$ ) for the aqueous phase or $0.2 \%$ Triton $\mathrm{X}-100$ (non-ionic surfactant) in $1 \% \mathrm{HNO}_{3}$ for the organic phase. The results were considered acceptable if 
mass balances of $100 \pm 10 \%$ were obtained. Afterwards, the distribution ratios $(D)$ of the individual cations were calculated as the ratio between the activity (or concentration) of a radioisotope (or stable element) in the organic phase and its activity (or concentration) in the aqueous phase. Taking into account the detection limits, the minimum and maximum distribution ratios are comprised between 0.01 and 100 . The uncertainty in this region is usually below $5 \%$, while the uncertainty can be higher outside these limits. The selectivity was estimated by the separation factors $(S F)$ which were calculated as the ratio between the distribution ratios of two different cations.

\section{Single-stage centrifugal contactor experiment}

The counter-current liquid liquid extraction experiment was carried out in a single-stage centrifugal contactor device (produced by Institute of Nuclear Energy Technology, Tsinghua University, Beijing, China) characterized by $6 \mathrm{~mL}$ total hold-up volume. The operational rotation speed of the centrifuge was set at $4500 \mathrm{rpm}$ in order to allow efficient phases separation. The above described TODGA based organic solvent was previously loaded from

Feed 2 (at $3 \mathrm{~mol} / \mathrm{L} \mathrm{HNO}_{3}$ and spiked with ${ }^{241} \mathrm{Am}(\mathrm{III}),{ }^{244} \mathrm{Cm}(\mathrm{III})$ and ${ }^{152} \mathrm{Eu}(\mathrm{III}), 5.15$ $\mathrm{kBq} / \mathrm{mL}, 5.55 \mathrm{kBq} / \mathrm{mL}$ and $9.25 \mathrm{kBq} / \mathrm{mL}$, respectively) and scrubbed with $0.5 \mathrm{~mol} / \mathrm{L} \mathrm{HNO}_{3}$ to limit the organic nitric acid concentration and to reduce the co-extraction of undesired fission and corrosion products. As described, $0.5 \mathrm{~mol} / \mathrm{L}$ CDTA was added to the feed to suppress the extraction of $\mathrm{Pd}$ and $\mathrm{Zr}$. Both extraction and scrubbing steps were performed by contacting aqueous and organic phases in glass Schott flasks. The mixing was performed by manual shaking for 15 minutes and the phases were allowed to settle down. After separation of the phases, aliquots were collected to verify mass balance and extraction performance. The stripping step was performed by feeding the previously loaded and scrubbed organic phase and the optimized stripping solution $\left(0.08 \mathrm{~mol} / \mathrm{L}\right.$ PyTri Diol in $\left.0.45 \mathrm{~mol} / \mathrm{L} \mathrm{HNO}_{3}\right)$ in the centrifugal contactor by duly calibrated syringe pumps. In order to investigate different 
contact times between organic and aqueous phases, forasmuch as the contactor chamber volume is constant, three different flow-rate conditions were tested by keeping $\mathrm{O} / \mathrm{A}$ volume ratio constant at a value of 2 . In the first one, the organic phase was introduced at $120 \mathrm{~mL} / \mathrm{h}$, while the aqueous phase was introduced at $60 \mathrm{~mL} / \mathrm{h}$, resulting in a phases contact time of 2 minutes. The second condition consisted of organic and aqueous phases fed at $80 \mathrm{~mL} / \mathrm{h}$ and $40 \mathrm{~mL} / \mathrm{h}$, respectively (phases contact time of 3 minutes). In the last condition the flow-rates were $60 \mathrm{~mL} / \mathrm{h}$ and $30 \mathrm{~mL} / \mathrm{h}$ for organic and aqueous phases, respectively; consequently a phase contact time of 4 minutes was reached. Each flow-rate condition was maintained until the steady state was confirmed by accompanying ${ }^{241} \mathrm{Am}(\mathrm{III})$ and ${ }^{152} \mathrm{Eu}(\mathrm{III}) \gamma$-measurement (10 minutes at the first condition, 20 minutes at the second and 26 minutes at the third one).

During each flow-rate change, the pumps were stopped, set to the new flow-rate and restarted, while the centrifuge was kept in operation. At the thirtieth minute the syringe containing the organic phase was refilled.

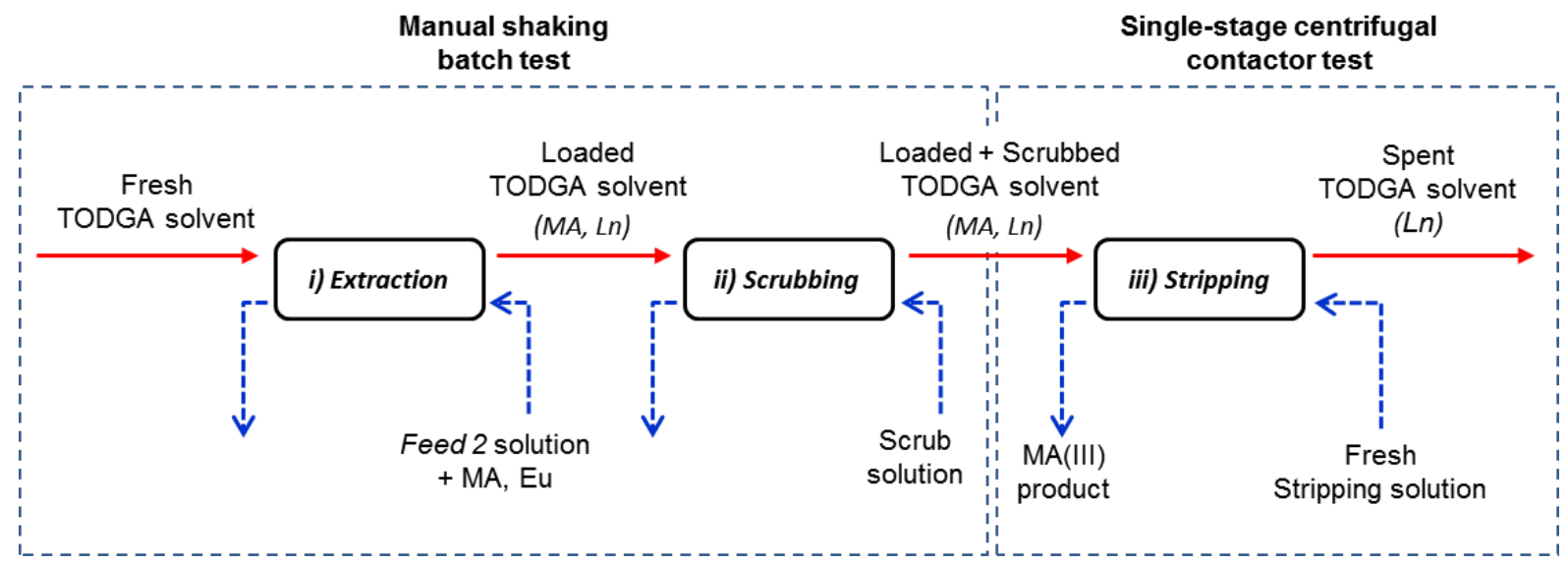

Figure 2. Schematic sketch of the single-stage centrifugal contactor experiment. Loading of fresh TODGA solvent $(0.2 \mathrm{~mol} / \mathrm{L}$ TODGA in TPH + 5 vol\% 1-octanol) by manual shaking batch extraction from Feed 2 (spiked with ${ }^{152} \mathrm{Eu}(\mathrm{III}),{ }^{241} \mathrm{Am}(\mathrm{III})$ and ${ }^{244} \mathrm{Cm}(\mathrm{III})$ at $\left.3 \mathrm{~mol} / \mathrm{L} \mathrm{HNO}+0.05 \mathrm{~mol} / \mathrm{L} \mathrm{CDTA}\right)$ and scrubbing with $0.5 \mathrm{~mol} / \mathrm{L} \mathrm{HNO}_{3}$. Stripping of trivalent MA from the loaded TODGA solvent by single-stage centrifugal contactor test with fresh stripping solution: $0.08 \mathrm{~mol} / \mathrm{L}$ PyTri-Diol in $0.45 \mathrm{~mol} / \mathrm{L} \mathrm{HNO}_{3}$. Organic flow-rates: i) $(0-10 \mathrm{~min}) 120 \mathrm{~mL} / \mathrm{h}$; ii) $(11$ $30 \mathrm{~min}) 80 \mathrm{~mL} / \mathrm{h}$; iii) (31-55 min) $60 \mathrm{~mL} / \mathrm{h}$.; aqueous flow-rates: i) $(0-10 \mathrm{~min}) 60 \mathrm{~mL} / \mathrm{h}$; ii) (11-30 min) $40 \mathrm{~mL} / \mathrm{h}$; iii) (31-55 min) $30 \mathrm{~mL} / \mathrm{h}$. 
For the subsequent analyses, several samples (transient and steady state samples) were collected on a regular basis during the centrifugal contactor experiment at the aqueous and organic outlets of the contactor. Therefore, no disturbance of the steady-state was caused. The vials accommodating the resulting aqueous and organic solutions were changed every minute for the first condition and every 2 minutes for the second and third one. Moreover, after the experiment, the centrifugal contactor was dismantled and the content of the mixing chamber was retrieved and mixed for 15 minutes by an orbital shaker in order to obtain the equilibrium samples. Two aliquots were derived from every sample for $\gamma$ measurement and ICP-MS analysis. Moreover, $\alpha$ spectrometric analyses were performed on selected samples in order to assess the distribution ratios of ${ }^{244} \mathrm{Cm}(\mathrm{III})$. Distribution ratios and separation factors were calculated as described above. Furthermore, the single-stage efficiency percentage (E\%) of the stripping step was calculated at each flow-rate condition according to the equation:

$E=\frac{C_{\text {load }}^{\text {org }}-C_{x}^{\text {org }}}{C_{\text {load }}^{\text {org }}-C_{e q}^{\text {org }}}$

where $C_{\text {load }}^{\text {org }}$ is the cation concentration in the loaded organic phase; $C_{x}^{\text {org }}$ is the cation concentration in the organic phase of the steady-state sample $x$ of the centrifugal contactor experiment; $C_{e q}^{o r g}$ is the cation concentration in the organic phase of the equilibrium sample [46]. Both $C_{x}^{o r g}$ and $C_{e q}^{o r g}$ were normalized to the $C_{\text {load }}^{\text {org }}$ value, taking into account the cation concentration in the respective aqueous phase.

\section{RESULTS AND DISCUSSION}

\section{Optimization of stripping phase composition on batch scale}

Preliminary batch solvent extraction tests were carried out in order to verify the optimal working conditions already outlined in a previous work [42]. 
A first experiment was performed focusing on the optimal $\mathrm{HNO}_{3}$ concentration for the stripping step. PyTri Diol was dissolved in several Feed 1 aqueous solutions with different initial $\mathrm{HNO}_{3}$ concentrations ranging from 0.13 to $1.15 \mathrm{~mol} / \mathrm{L}$. The results are reported in Table 2.

Table 2. Distribution ratios of trivalent Am and lighter $\mathrm{Ln}$ and $\mathrm{La}(\mathrm{III}) / \mathrm{Am}$ (III) separation factors as a function of initial $\mathrm{HNO}_{3}$ concentration. Organic phase: $0.2 \mathrm{~mol} / \mathrm{L}$ TODGA in TPH + $5 \mathrm{vol} . \%$ 1-octanol. Aqueous phase: $0.08 \mathrm{~mol} / \mathrm{L}$ PyTri-Diol in Feed 1, spiked with ${ }^{241} \mathrm{Am}(\mathrm{III})$ and ${ }^{152} \mathrm{Eu}(\mathrm{III})$, at different $\mathrm{HNO}_{3}$ concentration.

\begin{tabular}{ccccccc}
\hline & \multicolumn{5}{c}{ Distribution ratios } \\
\cline { 2 - 7 }$\left[\mathrm{HNO}_{3}\right]_{\text {in }} \mathrm{M}$ & 0.13 & 0.41 & 0.54 & 0.62 & 0.98 & 1.15 \\
\hline $\mathrm{La}$ & 0.209 & 2.18 & 5.88 & 8.5 & 22.2 & 35.1 \\
$\mathrm{Ce}$ & 0.240 & 3.06 & 9.38 & 14.4 & 35.4 & $>100$ \\
$\mathrm{Pr}$ & 0.266 & 4.09 & 13.4 & 22.9 & 97.9 & $>100$ \\
$\mathrm{Nd}$ & 0.326 & 6.77 & 33.4 & 92.1 & $>100$ & $>100$ \\
$\mathrm{Sm}$ & 0.550 & 18.3 & $>100$ & $>100$ & $>100$ & $>100$ \\
$\mathrm{Eu}$ & 0.542 & 20.3 & $>100$ & $>100$ & $>100$ & $>100$ \\
$\mathrm{Gd}$ & 0.507 & 19.3 & 90.7 & 94.0 & 98.3 & $>100$ \\
${ }^{152} \mathrm{Eu}$ & 0.668 & 36.7 & $>100$ & $>100$ & $>100$ & $>100$ \\
${ }^{241} \mathrm{Am}$ & 0.001 & 0.109 & 0.532 & 1.09 & 13.3 & 30.9 \\
\hline$S F_{\mathrm{La} / \mathrm{Am}}$ & 186 & 20.1 & 11.1 & 7.84 & 1.67 & 1.14 \\
\hline
\end{tabular}

The presence of PyTri-Diol as hydrophilic complexing agent suppresses the extraction of Am(III), while the effect on the $\operatorname{Ln}(\mathrm{III})$ is less pronounced if compared with literature data on TODGA behavior [45]. Distribution ratios of Am(III) are significantly lower compared to the $\mathrm{Ln}(\mathrm{III})$. Thus, the selectivity of the $\mathrm{N}_{3}$-donor site for MA(III) towards $\mathrm{Ln}(\mathrm{III})$ is confirmed. Moreover, the distribution ratios of both Am(III) and Ln(III) increase with increasing initial $\mathrm{HNO}_{3}$ concentration, as usually observed for solvating extracting agents [47] such as diglycolamide extractants $[30,37]$. The optimal nitric acid concentration for a selective stripping of $\mathrm{An}(\mathrm{III})$ is at about $0.4 \mathrm{~mol} / \mathrm{L} \mathrm{HNO}_{3}$. $\mathrm{Ln}(\mathrm{III}) / \mathrm{MA}(\mathrm{III})$ separation can be effectively achieved since $D_{\mathrm{Am}}$ is about 0.1 while the distribution ratios of all $\mathrm{Ln}$ are greater than 1, with a separation factor between the least extracted lanthanide (La) and Am(III) of 
approximately 20 at $0.4 \mathrm{~mol} / \mathrm{L} \mathrm{HNO}_{3}$. However, this property decreases with increasing $\mathrm{HNO}_{3}$ concentration, due to the competing complexing agent protonation $[42,43]$.

Additionally, the influence of PyTri-Diol concentration on the distribution ratios of trivalent Am and Ln was studied. For this purpose, weighted amounts of PyTri-Diol were dissolved in Feed 1 at $0.4 \mathrm{~mol} / \mathrm{L} \mathrm{HNO}_{3}$ to obtain different ligand concentrations, ranging from 0.01 to 0.1 mol/L PyTri-Diol. Figure 3 shows the distribution ratios of trivalent cations as a function of the PyTri-Diol concentration.

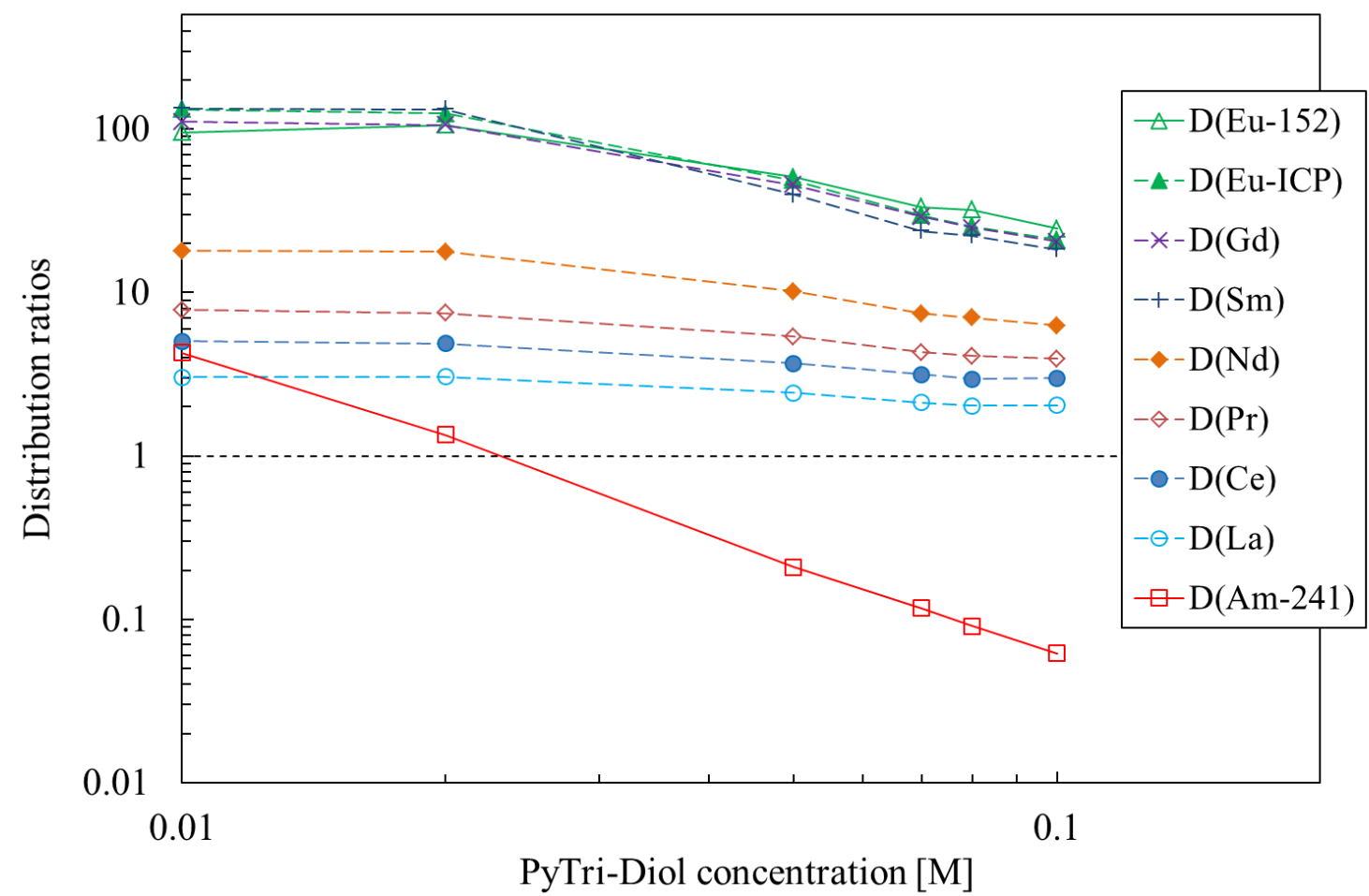

Figure 3. Distribution ratios of trivalent $\mathrm{Am}$ and lighter $\mathrm{Ln}$ as a function of PyTri-Diol concentration. Organic phase: $0.2 \mathrm{~mol} / \mathrm{L}$ TODGA in TPH + 5 vol.\% 1-octanol. Aqueous phase: Feed 1 at $0.4 \mathrm{~mol} / \mathrm{L} \mathrm{HNO}_{3}$ concentration, spiked with ${ }^{241} \mathrm{Am}(\mathrm{III})$ and ${ }^{152} \mathrm{Eu}(\mathrm{III})$, with different PyTri-Diol concentrations.

Distribution ratios of Am(III) decrease with increasing PyTri-Diol concentration. On the contrary, Ln(III) distribution ratios are less affected as their distribution ratios decrease only slightly, confirming the high affinity of PyTri-Diol for Am(III). Consequently, the Ln(III)/Am(III) separation factor increases with increasing PyTri-Diol concentration. The 
distribution ratios of the lighter $\mathrm{Ln}(\mathrm{La}, \mathrm{Ce}$ and $\mathrm{Pr}$ ) are nearly constant, while the heavier $\mathrm{Ln}$ (especially Eu, Gd and Sm) show a significant decrease of distribution ratios at higher PyTriDiol concentrations. Coherently with a previous work, the slope of $\log (D)$ vs $\log [L]$, where $[L]$ is the concentration of PyTri-Diol, is about -1.87 for Am(III) and -0.91 for Eu(III) [42]. This entails the formation of 1:2 and 1:1 cation to ligand complexes for Am(III) and Eu(III), respectively. The discrepancy in the complexation stoichiometry is evidenced, as compared with the results of a spectroscopic study, where prevalent 1:3 cation-ligand complexation was shown at process conditions [43]. This apparent inconsistency has been previously highlighted in other studies on different hydrophilic complexing agents $[38,48,49]$ and is the topic of current investigation. The separation factors between Ln(III) and Am(III) increase with increasing PyTri-Diol concentration. The target process requirements of a separation factor greater than 10 are successfully fulfilled for PyTri Diol concentration greater than 0.05 $\mathrm{mol} / \mathrm{L}$, since $D_{\mathrm{Am}}$ is about 0.2 while the distribution ratios of all Ln are above 1 [42]. The separation factor between the least extracted Ln (La) and Am(III) is approximately 11. Prompted by these promising results, further experiments were performed with the more representative Feed 2 additionally containing fission and corrosion products in realistic concentrations, in order to verify the optimized stripping solvent formulation for conditions similar to the $i$-SANEX process. The loaded and scrubbed TODGA organic phase was contacted with PyTri-Diol solutions of different acidities and complexant concentrations, in order to study the influence on the distribution ratios of co-extracted elements. Table 3 shows the distribution ratios of trivalent $\mathrm{Am}, \mathrm{Ln}$, and $\mathrm{Ru}$ at different initial $\mathrm{HNO}_{3}$ concentrations. 
Table 3. Distribution ratios of Ru, trivalent Am and Ln and separation factors of La(III)/Am(III) and Ru/Am(III) as a function of initial $\mathrm{HNO}_{3}$ concentration. Organic phase: $0.2 \mathrm{~mol} / \mathrm{L}$ TODGA in kerosene $+5 \mathrm{vol} . \%$ 1-octanol loaded from Feed 2, spiked with ${ }^{152} \mathrm{Eu}(\mathrm{III})$ and ${ }^{241} \mathrm{Am}(\mathrm{III})$ at $3 \mathrm{~mol} / \mathrm{L} \mathrm{HNO}_{3}+0.05 \mathrm{~mol} / \mathrm{L} \mathrm{CDTA}$, and scrubbed with $0.5 \mathrm{~mol} / \mathrm{L} \mathrm{HNO}_{3}$. Aqueous phase: $0.08 \mathrm{~mol} / \mathrm{L}$ PyTri-Diol in different $\mathrm{HNO}_{3}$ concentration.

\begin{tabular}{ccccc}
\hline & \multicolumn{4}{c}{ Distribution ratios } \\
\cline { 2 - 5 }$\left[\mathrm{HNO}_{3}\right]_{\text {in }} \mathrm{M}$ & 0.35 & 0.43 & 0.57 & 0.69 \\
\hline $\mathrm{Ru}$ & 5.10 & 5.96 & 10.6 & 10.9 \\
$\mathrm{La}$ & 0.73 & 1.25 & 2.14 & 3.06 \\
$\mathrm{Ce}$ & 1.05 & 1.85 & 3.25 & 4.83 \\
$\mathrm{Pr}$ & 1.44 & 2.63 & 4.89 & 7.51 \\
$\mathrm{Nd}$ & 2.32 & 4.44 & 8.43 & 13.6 \\
$\mathrm{Sm}$ & 6.27 & 14.5 & 25.6 & 45.0 \\
$\mathrm{Eu}$ & 9.14 & 21.5 & 36.7 & 69.0 \\
$\mathrm{Gd}$ & 5.32 & 10.4 & 19.7 & 32.9 \\
${ }^{152} \mathrm{Eu}$ & 11.8 & 25.1 & 57.5 & 86.5 \\
${ }^{241} \mathrm{Am}$ & 0.028 & 0.086 & 0.274 & 0.598 \\
\hline$S F_{\mathrm{La} / \mathrm{Am}}$ & 26.6 & 14.5 & 7.81 & 5.12 \\
$S F_{\mathrm{Ru} / \mathrm{Am}}$ & 185 & 69.0 & 38.5 & 18.2 \\
\hline
\end{tabular}

The distribution ratios of the selected elements increase with increasing nitric acid concentration. The investigation of ruthenium behavior is worthwhile, since its co-extraction by the TODGA solvent could not be completely prevented [32,33,41]. It is well-known that different $\mathrm{Ru}$ species can form in nitric acid, thus influencing the extraction experiments results. As well, the chemical form of Ru added to the simulant feed solution has to be acknowledged. Similarly to previous TODGA process tests [31-32] that produced comparable results with a hot test of the same system using genuine fuel solution [22], Ru was added to the synthetic feed solution in the form of nitrosyl-nitrate salt. Therefore, the obtained Ru speciation can be assumed representative of that in genuine fuel solutions. The distribution ratios of other fission and corrosion products are not reported since they were not present in significant amounts in the TODGA organic phase after the scrubbing step [41]. The optimal $\mathrm{HNO}_{3}$ concentration of the stripping solution is about $0.42 \mathrm{~mol} / \mathrm{L} \mathrm{HNO}_{3}$. In this condition, all fission and corrosion products manifest distribution ratios greater than 1 while 
$D_{\mathrm{Am}}$ is approximately 0.1 . Moreover, $S F_{\mathrm{La} / \mathrm{Am}}$ is 14.5 and $S F_{\mathrm{Ru} / \mathrm{Am}}$ is 69.0 , successfully meeting the requirements for the development of a continuous counter current process. The slight differences between results of Table 2 and Table 3 should be mainly ascribed to loading effects due to the different feeds being used in the experiments, dilute Ln and HAR simulate solutions respectively.

Similar investigations were conducted focusing on the influence of the PyTri-Diol concentration on distribution ratios of co-extracted metal ions. Table 4 shows the distribution ratios of trivalent Am, Ln, and Ru as a function of the PyTri-Diol concentration dissolved in $0.42 \mathrm{~mol} / \mathrm{L} \mathrm{HNO}_{3}$. Distribution ratios of Am(III) strongly decrease with increasing PyTriDiol concentration. The Ln(III) are less affected by a change of the complexant concentration. Only at higher PyTri-Diol concentrations a slight decrease of Eu and Gd distribution ratios is observed. In agreement with a previous work, PyTri-Diol concentration of $0.08 \mathrm{~mol} / \mathrm{L}$ is required in order to obtain $S F_{\mathrm{La} / \mathrm{Am}}$ of above 10 in presence of simulated PUREX raffinate [42]. Furthermore, ruthenium back extraction seems to be unaffected by modifications of the complexant concentration as its distribution ratios are constantly greater than unity. 
Table 4. Distribution ratios of Ru, trivalent Am and Ln and separation factors of La(III)/Am(III) and Ru/Am(III) as a function of the PyTri-Diol concentration. Organic phase: $0.2 \mathrm{~mol} / \mathrm{L}$ TODGA in TPH $+5 \mathrm{vol} . \%$ 1-octanol loaded from Feed 2, spiked with ${ }^{152} \mathrm{Eu}(\mathrm{III})$ and ${ }^{241} \mathrm{Am}$ (III) at $3 \mathrm{~mol} / \mathrm{L} \mathrm{HNO}_{3}+0.05 \mathrm{~mol} / \mathrm{L}$ CDTA) and scrubbed with $0.5 \mathrm{~mol} / \mathrm{L} \mathrm{HNO}_{3}$. Aqueous phase: different PyTri-Diol concentration in $0.425 \mathrm{~mol} / \mathrm{L} \mathrm{HNO}_{3}$.

\begin{tabular}{cccccc}
\hline & \multicolumn{5}{c}{ Distribution ratios } \\
\cline { 2 - 6 }$[$ PyTri-Diol] M & 0.01 & 0.03 & 0.06 & 0.08 & 0.1 \\
\hline $\mathrm{Ru}$ & 7.03 & 5.88 & 8.48 & 5.96 & 5.48 \\
$\mathrm{La}$ & 1.48 & 1.47 & 1.35 & 1.25 & 1.16 \\
$\mathrm{Ce}$ & 2.39 & 2.29 & 2.05 & 1.85 & 1.67 \\
$\mathrm{Pr}$ & 3.68 & 3.40 & 2.98 & 2.63 & 2.32 \\
$\mathrm{Nd}$ & 6.64 & 5.90 & 5.20 & 4.44 & 3.79 \\
$\mathrm{Sm}$ & 22.7 & 18.0 & 17.4 & 14.5 & 10.6 \\
$\mathrm{Eu}$ & 33.2 & 25.7 & 26.6 & 21.5 & 15.1 \\
$\mathrm{Gd}$ & 16.5 & 13.3 & 12.7 & 10.4 & 7.54 \\
${ }^{152} \mathrm{Eu}$ & 46.4 & 45.6 & 33.5 & 25.1 & 20.2 \\
${ }^{241} \mathrm{Am}$ & 3.01 & 0.567 & 0.152 & 0.086 & 0.061 \\
\hline$S F_{\mathrm{La} / \mathrm{Am}}$ & 0.49 & 2.60 & 8.94 & 14.5 & 19.0 \\
$S F_{\mathrm{Ru} / \mathrm{Am}}$ & 2.34 & 10.4 & 55.9 & 69.0 & 89.8 \\
\hline
\end{tabular}

These preliminary batch tests showed that the PyTri-Diol based stripping solution provides high selectivity for trivalent Am over Ln in forward and backward extraction modes, not only with trace concentrations of fission and corrosion product ions but also with an organic phase loaded from a spiked synthetic feed simulating the PUREX raffinate. The optimal solvent formulation gathered by these experiments was found to be $0.08 \mathrm{~mol} / \mathrm{L}$ PyTri-Diol in 0.44 mol/L $\mathrm{HNO}_{3}$. Except for Ru that turned out to be uninfluenced by PyTri-Diol, the fission and corrosion products should not represent a problem in a TODGA-based counter-current process.

\section{Single-stage centrifugal contactor experiment}

Studies on novel chemical systems to be used in SNF reprocessing are usually performed as batch experiments, in order to identify the ideal working conditions. Afterwards, if these preliminary results are promising enough to deserve further investigations, small-scale tests are performed in dedicated devices in order to ascertain the process feasibility and determine 
the scaling up factors for a pilot or industrial plant [50,51]. In particular, single-stage centrifugal contactor experiments are performed to identify the optimal conditions for the multi-stage test and determine the effect of single-stage efficiency on separation factors achievable in this device, since predictions cannot be based on equilibrium $D$ values. The final aim of running single-stage experiments is the calculation of process flow-sheet on the single-stage efficiencies.

In order to design the flow-sheet of a novel $i$-SANEX process based on a combination of TODGA and PyTri-Diol, a single-stage experiment was performed within this experimental campaign and the results are herein described. First and foremost, neither precipitate formation nor hydrodynamic problems were encountered during the whole centrifugal contactor experiment. Satisfactory mass balances were obtained as well. The distribution ratios of $\mathrm{Ru}$, trivalent $\mathrm{Y}, \mathrm{Ln}$, and MA of the transient and steady-state subsamples are reported in Figure 4 as a function of experiment runtime.

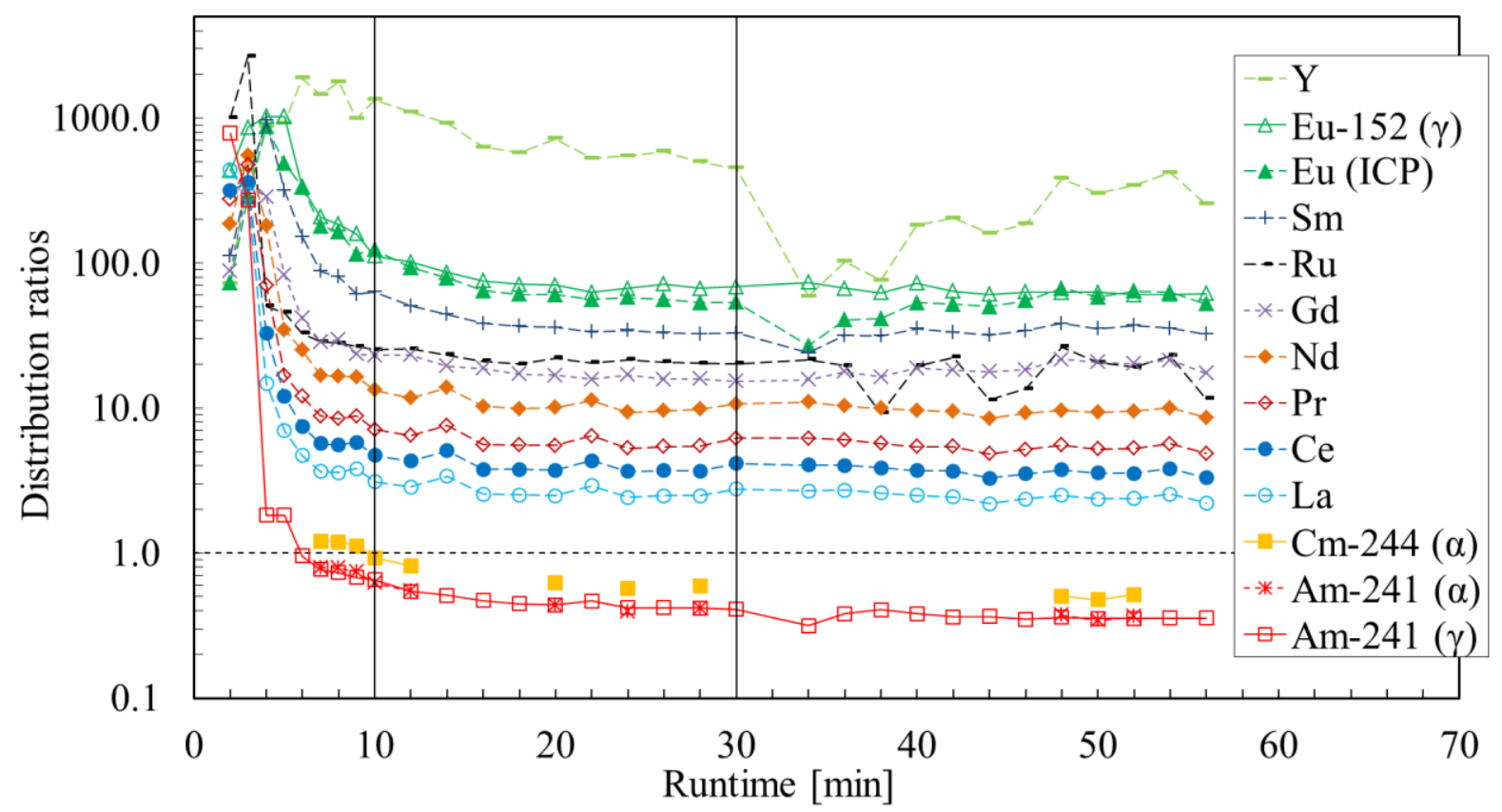

Figure 4. Distribution ratios of ${ }^{241} \mathrm{Am}$ (III), ${ }^{244} \mathrm{Cm}$ (III), ${ }^{152} \mathrm{Eu}(\mathrm{III}), \mathrm{Ru}, \mathrm{Y}$ (III) and $\mathrm{Ln}$ (III) as a function of experiment runtime expressed in minutes. The vertical lines delimitate the three flow-rate conditions adopted in the experiment. Organic phase: $0.2 \mathrm{~mol} / \mathrm{L}$ TODGA in TPH $+5 \mathrm{vol} \%$ 1-octanol, previously loaded from Feed 2 (spiked with ${ }^{152} \mathrm{Eu}(\mathrm{III})$, ${ }^{241} \mathrm{Am}(\mathrm{III})$ and ${ }^{244} \mathrm{Cm}(\mathrm{III})$ at $3 \mathrm{~mol} / \mathrm{L} \mathrm{HNO}_{3}+0.05 \mathrm{~mol} / \mathrm{L}$ CDTA) and scrubbed with $0.5 \mathrm{~mol} / \mathrm{L} \mathrm{HNO}_{3}$, organic flowrates: i) $(0-10 \mathrm{~min}) 120 \mathrm{~mL} / \mathrm{h}$; ii) $(11-30 \mathrm{~min}) 80 \mathrm{~mL} / \mathrm{h}$; iii) $(31-55 \mathrm{~min}) 60 \mathrm{~mL} / \mathrm{h}$. Aqueous phase: 0.08 mol/L PyTriDiol in 0.45 mol/L $\mathrm{HNO}_{3}$, aqueous flow-rates: i) $(0-10 \mathrm{~min}) 60 \mathrm{~mL} / \mathrm{h}$; ii) $(11-30 \mathrm{~min}) 40 \mathrm{~mL} / \mathrm{h}$; iii) $(31-55 \mathrm{~min})$ $30 \mathrm{~mL} / \mathrm{h}$. 
Distribution ratios of ${ }^{241} \mathrm{Am}(\mathrm{III})$ resulting from gamma and alpha spectrometry are comparable. Moreover, trivalent ${ }^{152} \mathrm{Eu}\left(\gamma\right.$ spectrometry) and ${ }^{153} \mathrm{Eu}(\mathrm{ICP}-\mathrm{MS})$ results manifest similar coherence. After a brief initial transient (about 5 minutes), the distribution ratios stabilize and keep almost unchanged within the three flow-rate conditions. The results are very encouraging: the separation of MA(III) from Y(III) and Ln(III) can be successfully achieved with good safety margins towards unforeseen flow-rates conditions alterations. In fact, while the MA(III) manifested distribution ratios definitely below unity, that of the least extracted trivalent $\mathrm{Ln}(\mathrm{La})$ turned out to be constantly greater than 2. Consequently, the $\mathrm{La}(\mathrm{III}) / \mathrm{MA}(\mathrm{III})$ separation factor is approximately 7, adequate for the development of an efficient TODGA-PyTri-Diol based $i$-SANEX process. Even though ${ }^{244} \mathrm{Cm}$ (III) distribution ratios are slightly higher than those of ${ }^{241} \mathrm{Am}(\mathrm{III})$, they exhibit a similar trend as a function of runtime. Moreover, as expected from previous results, the separation of $\mathrm{Cm}(\mathrm{III})$ over Am(III) is rather low, with $S F_{\mathrm{Cm} / \mathrm{Am}}$ of about 1.4 at steady state condition versus 1.1 at equilibrium [42]. Furthermore, the presence of fission and corrosion products does not compromise PyTri-Diol performances. Special attention should be dedicated to ruthenium. In fact, it is known from previous works that this element is present in the loaded organic solvent after co-extraction and scrubbing steps with ca. $16 \%$ of its initial mass $[32,33,41]$. Consequently, it has to be carefully monitored so as to ascertain that its distribution ratio is above 1 in order to avoid contamination of the MA product solution. In compliance with this requirement, distribution ratios of this element were found to be far above unity (greater than 20, see Table 5). The other fission and corrosion products present in the synthetic feed (e.g.: Sr, Mo, Pd) are meaningless for the stripping stages as they were already removed during the extraction/scrubbing sections [41]. Along with the satisfactory trivalent MA/Ln separation, these results are very encouraging concerning fission and corrosion products for the 
candidacy of the TODGA - PyTri-Diol system as promising solvent-stripping combination for the development of a novel $i$-SANEX flow-sheet.

The distribution ratios of major cations obtained for steady-state and equilibrium samples are reported in Table 5. Even if the distribution ratios at steady-state are consistently higher than those obtained for the equilibrium, it appears evident that trivalent MA/Ln separation is feasible. The steady states Am(III) distribution ratios (and only to a lesser extent, also the $\mathrm{Ln}$ (III) distribution ratios) are higher than those at equilibrium, whether obtained by batch tests or by re-shaking the effluent samples from the single-stage centrifuge runs.

Consequently, $S F_{\mathrm{La} / \mathrm{Am}}$ obtained in single-stage centrifugal contactor experiment are lower than at equilibrium. This issue could be overcome by reducing the flow-rates, thus increasing the phase contact time in the contactor. The single-stage percentage efficiencies of $\mathrm{Ru}$, trivalent Y, Ln, and MA are reported in Table 5. Even if the TODGA - PyTri-Diol system is endowed with fast kinetics in batch experiments [42], it can be inferred that lower flow-rates entail higher stage efficiency in centrifugal contactor equipment. In fact, the phase transfer kinetics and, consequently, the stage efficiencies increase moving from the first flow-rate condition to the second and the third ones. Moreover, the Am(III) and $\mathrm{Cm}$ (III) efficiencies reach the satisfactory values of respectively $69 \%$ and $61 \%$, while those of the $\operatorname{Ln}(\mathrm{III})$ are in the range of $30-50 \%$ and exceed 50\% only in the case of La and Ce. Probably due to higher PyTri-Diol affinity towards MA(III), the manifested lower stage efficiency for Ln(III) is beneficial since it will repress their release into the aqueous phase along with MA(III). On the other hand, increasing Am(III) and Cm(III) stage efficiency could be conveniently achieved by further reducing flow-rates, e.g. down to $40 / 20 \mathrm{~mL} / \mathrm{h}$ for the organic and aqueous phases respectively. 
Table 5. Distribution ratios and single-stage percentage efficiencies of Ru, trivalent $\mathrm{Y}$, Ln, and MA and separation factors of $\mathrm{La}(\mathrm{III}) / \mathrm{Am}$ (III) and $\mathrm{Ru} / \mathrm{Am}$ (III) in steady-states (three flow-rate conditions), and in equilibrium. The results of the first flow-rate condition belong to its last sampling point (at ninth minute), while those of the second and third ones are the average values of three sampling points (respectively from 24 to 28 minutes and from 50 to 54 minutes).

\begin{tabular}{|c|c|c|c|c|c|c|c|}
\hline & \multicolumn{6}{|c|}{ "Steady-state" O/A flow-rate $[\mathrm{mL} / \mathrm{h}]$} & \multirow{3}{*}{$\begin{array}{c}\text { Equilibrium } \\
D\end{array}$} \\
\hline & \multicolumn{2}{|c|}{$120 / 60$} & \multicolumn{2}{|c|}{$80 / 40$} & \multicolumn{2}{|c|}{$60 / 30$} & \\
\hline & $D$ & $E \%$ & $D$ & $E \%$ & $D$ & $E \%$ & \\
\hline $\mathrm{Ru}$ & 26.6 & $38 \%$ & 20.9 & $48 \%$ & 20.9 & $48 \%$ & 6.27 \\
\hline Y & $>100$ & $8 \%$ & $>100$ & $14 \%$ & $>100$ & $21 \%$ & 74.2 \\
\hline $\mathrm{La}$ & 3.83 & $38 \%$ & 2.47 & $56 \%$ & 2.43 & $56 \%$ & 1.15 \\
\hline $\mathrm{Ce}$ & 5.79 & $35 \%$ & 3.68 & $53 \%$ & 3.66 & $54 \%$ & 1.73 \\
\hline $\operatorname{Pr}$ & 8.81 & $31 \%$ & 5.40 & $49 \%$ & 5.39 & $49 \%$ & 2.41 \\
\hline $\mathrm{Nd}$ & 16.4 & $26 \%$ & 9.58 & $44 \%$ & 9.62 & $44 \%$ & 3.94 \\
\hline $\mathrm{Sm}$ & 61.2 & $22 \%$ & 33.4 & $39 \%$ & 36.0 & $37 \%$ & 12.8 \\
\hline $\mathrm{Eu}$ & $>100$ & $16 \%$ & 55.7 & $34 \%$ & 61.7 & $31 \%$ & 18.6 \\
\hline $\mathrm{Gd}$ & 23.6 & $39 \%$ & 16.2 & $57 \%$ & 20.8 & $45 \%$ & 8.98 \\
\hline${ }^{152} \mathrm{Eu}(\gamma)$ & $>100$ & $14 \%$ & 68.5 & $32 \%$ & 61.4 & $35 \%$ & 21.4 \\
\hline${ }^{241} \mathrm{Am}(\gamma)$ & 0.68 & $49 \%$ & 0.42 & $63 \%$ & 0.35 & $68 \%$ & 0.08 \\
\hline${ }^{241} \mathrm{Am}(\alpha)$ & 0.74 & $52 \%$ & 0.41 & $55 \%$ & 0.35 & $69 \%$ & 0.08 \\
\hline${ }^{244} \mathrm{Cm}(\alpha)$ & 1.12 & $42 \%$ & 0.58 & $56 \%$ & 0.50 & $61 \%$ & 0.10 \\
\hline$S F_{\mathrm{La} / \mathrm{Am}}$ & 5.63 & & 5.90 & & 6.86 & & 13.8 \\
\hline$S F_{\mathrm{Ru} / \mathrm{Am}}$ & 39.1 & & 49.9 & & 58.9 & & 75.2 \\
\hline
\end{tabular}

\section{Flow-Sheet Calculations}

A flow-sheet for the MA(III)-Ln(III) separation section to be implemented in an $i$-SANEX process run was calculated. This section consists of two sub-sections, one for stripping Am(III) and $\mathrm{Cm}$ (III) from the loaded organic phase using an aqueous solution containing PyTri-Diol, one for re-extracting co-stripped Ln(III), see Figure 5.

Calculations were performed using the SX Process code [52] [53]. Distribution data from above batch and single-stage centrifugal contactor experiments were used. Since no singlestage results for the re-extraction of $\operatorname{Ln}(\mathrm{III})$ is available, stage efficiency for this sub-section was estimated based on results from the $i$-SANEX process run using $\mathrm{SO}_{3}-\mathrm{Ph}-\mathrm{BTP}$ [37]. 
Recoveries were calculated for Am(III), La(III) (which has distribution ratios closest to those of $\mathrm{Am})$, and $\mathrm{Eu}(\mathrm{III})$. The proposed flow-sheet is shown in Figure 5.

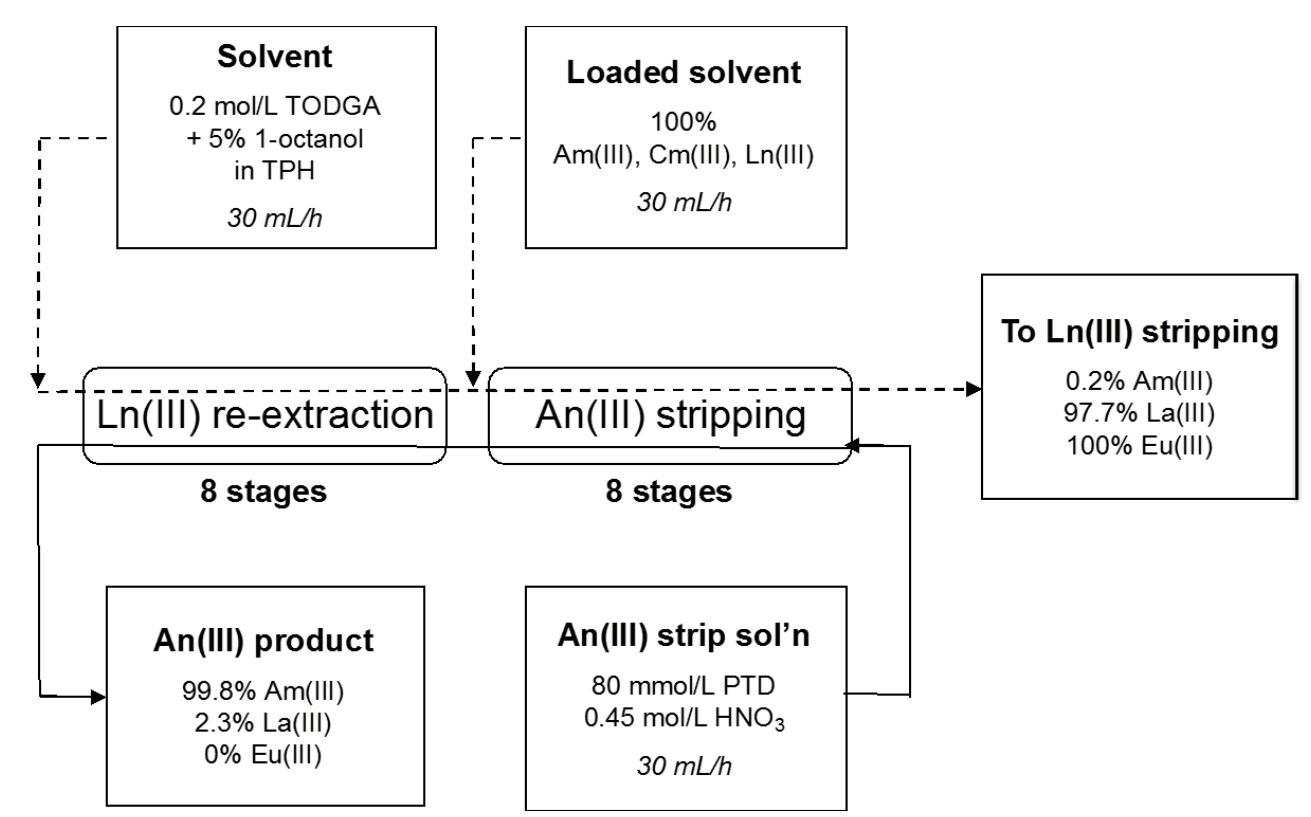

Figure 5. Proposed flow-sheet for the MA(III)-Ln(III) separation section. Recoveries calculated using the SX Process code.

In total, 16 stages are used for this section as this is the number of centrifugal contactors available to run a spiked demonstration test. The stages are evenly distributed between the two sub-sections. Flow-rates are $30 \mathrm{~mL} / \mathrm{h}$. The calculations indicate that $99.8 \%$ of Am(III) should be recovered in the $\mathrm{An}$ (III) product solution, together with $2.3 \%$ of $\mathrm{La}(\mathrm{III})$ and practically zero $\mathrm{Eu}(\mathrm{III})$. It is worth noticing that $\mathrm{Am}(\mathrm{III})$ and $\mathrm{Eu}(\mathrm{III})$ recoveries are essentially insensitive to the respective stage efficiencies in the $\mathrm{Ln}(\mathrm{III})$ re-extraction section; $\mathrm{La}$ (III) recovery is slightly affected. However, using a La(III) stage efficiency of $100 \%$ in the Ln(III) re-extraction section the $\mathrm{La}(\mathrm{III})$ loss to the $\mathrm{An}(\mathrm{III})$ product solution is expected to be only slightly reduced, from $2.3 \%$ down to $1.6 \%$. 


\section{CONCLUSIONS}

The CHON compliant and radiochemically stable PyTri-Diol complexing agent was successfully tested in a single-stage centrifugal contactor experiment, after optimization of the stripping phase formulation by focused batch tests. The obtained results are encouraging since no hydrodynamic hindrance was encountered and, as expected from batch data, promising trivalent minor actinides separation from lanthanides and other cations was achieved with sufficiently large safety margins towards unforeseen flow-rates condition alteration. A separation factor of about 7 between the least extracted trivalent lanthanide (La) and Am(III) was obtained. Furthermore, satisfactory Am(III) stage efficiency of $69 \%$ was achieved, while $\operatorname{Ln}(\mathrm{III})$ manifested lower efficiencies, beneficial for limited contamination of the minor actinides product solution. Moreover, PyTri-Diol turned out to be undisturbed by ruthenium, typically one of the most problematic fission products, while $\mathrm{Cm}$ (III)/Am(III) separation was not achievable. This successful single-stage centrifugal contactor experiment prepared the ground for further investigations of this novel system in a multi-stage setup. Further efforts should be dedicated to improve the MA(III) phase transfer kinetics and, consequently, their stage efficiency, in order to obtain even higher MA(III)/Ln(III) separation yields.

\section{ACKNOWLEDGEMENT}

This work has been supported by the EU-FP7 SACSESS project (Grant no. 323282), EU-H2020 GENIORS project (Grant no. 755171) and the Italian Ministry of Education, University and Research.

\section{REFERENCES}


[1] IAEA. Climate change and nuclear power. CCANP-14; International Atomic Energy Agency, Vienna, 2014.

[2] IAEA, Nuclear Technology Review 2016 - Report by the Director General. GC(60)/INF/2; International Atomic Energy Agency, Vienna, 2016.

[3] IAEA, Storage of spent nuclear fuel. Safety Standards Series No. SSG-15; ISSN 1020-525X; International Atomic Energy Agency, Vienna, 2012.

[4] IAEA, Management of reprocessed uranium. TECDOC 1529; ISSN 1011-4289; International Atomic Energy Agency, Vienna, 2007.

[5] IAEA, Nuclear fuel cycle information system. TECDOC 1613; ISSN 1011-4289; International Atomic Energy Agency, Vienna, 2009.

[6] Poinssot, Ch.; Bourg, S.; Boullis, B. Improving the nuclear energy sustainability by decreasing its environmental footprint. Guidelines from life cycle assessment simulations. Prog. Nucl. Energ., 2016, 92, 234-241.

[7] OECD-NEA, Potential benefits and impacts of advanced nuclear fuel cycles with actinide partitioning and transmutation. Technical Report 6894; ISBN 978-92-6499165-1; Nuclear Energy Agency, Paris, 2011.

[8] Poinssot, Ch.; Bourg, S.; Ouvrier, N.; Combernoux, N.; Rostaing, C.; VargasGonzales, M.; Bruno, J. Assessment of the environmental footprint of nuclear energy systems. Comparison between closed and open fuel cycles. Energy, 2014, 69, 199211.

[9] IAEA, Implications of partitioning and transmutation in radioactive waste management. Technical Reports Series 435; ISSN 0074-1914; International Atomic Energy Agency, Vienna, 2004. 
[10] Taylor, R. J.; Gregson, C. R.; Carrott, M. J.; Mason, C.; Sarsfield, M. J. Progress towards the full recovery of neptunium in an advanced PUREX process. Solvent Extr. Ion Exch., 2013, 31, 442-462.

[11] Nash, K. L.; Madic, C.; Mathur, J. N.; Lacquement, J. Actinide separation science and technology (Chapter 22). In The chemistry of actinides and transactinide elements, Morss, L.R., Edelstein, N.M., Fuger, J., Kats, J.J. (Eds.), Springer, 2006, 2622-2798.

[12] IAEA, Advanced reactor technology options for utilization and transmutation of actinides in spent nuclear fuel. TECDOC 1626; ISSN 1011-4289; International Atomic Energy Agency, Vienna, 2009.

[13] Modolo, G.; Geist, A.; Miguirditchian, M. Minor actinide separations in the reprocessing of spent nuclear fuels: recent advances in Europe (Chapter 10). In Reprocessing and recycling of spent nuclear fuel, Elsevier Ltd. (Ed.), 2015, 245-287.

[14] Musikas, C.; Le Marois, G.; Fitoussi, R.; Cuillerdier, C. Properties and use of nitrogen and sulfur donors in actinide separations. In Navratil, J. D., Schultz, W. W. (Eds.) ACS Symposium Series, Vol. 117, 1980.

[15] Musikas, C.; Vitorge, P.; Pattee, D. Progress in trivalent actinide lanthanide group separations. Presented at the $9^{\text {th }}$ International Solvent Extraction Conference, Denver, Colorado, USA, Aug 26 1983.

[16] Kolarik, Z. Complexation and separation of lanthanides(III) and actinides(III) by heterocyclic N-donors in solutions. Chem. Rev., 2008, 108, 4208-4252.

[17] Bhattacharyya, A.; Mohapatra, P. K.; Manchanda, V. K. Role of ligand softness and diluent on the separation behavior of Am(III) and $\mathrm{Eu}(\mathrm{III})$. J. Radioanal. Nucl. Chem.,. 2011, 288, 709-716. 
[18] Modolo, G.; Kluxen, P.; Geist, A. Demonstration of the LUCA process for the separation of americium(III) from curium(III), californium(III), and lanthanides(III) in acidic solution using a synergistic mixture of bis(chlorophenyl)dithiophosphinic acid and tris(2-ethylhexyl)phosphate. Radichim. Acta, 2010, 98, 193-201.

[19] Panak, P.; Geist, A. Complexation and Extraction of Trivalent Actinides and Lanthanides by Triazinylpyridine N Donor Ligands. Chem. Rev., 2013, 113, 11991236.

[20] Sood, D. D.; Patil, S. K. Chemistry of nuclear fuel reprocessing: current status. J. Radioanal. Nucl. Chem., 1996, 203, 547-573.

[21] Shultz, W. W.; Horwitz, E. P. The TRUEX process and the management of liquid TRU waste. Sep. Sci. Tech., 1988, 23, 1190-1210.

[22] Magnusson, D.; Christiansen, B.; Foreman, M. R. S.; Geist, A.; Glatz, J.-P.; Malmbeck, R.; Modolo, G.; Serrano-Purroy, D.; Sorel, C. Demonstration of a SANEX process in centrifugal contactors using the $\mathrm{CyMe}_{4}$-BTBP molecule on a genuine fuel solution. Solvent Extr. Ion Exch., 2009, 27, 97-106.

[23] Nash, K. L. The chemistry of TALSPEAK: a review of the science. Solvent Extr. Ion Exch., 2015, 33, 1-55.

[24] Lumetta, G. J.; Levitskaia, T. G.; Wilden, A.; Casella, A. J.; Hall, G. B.; Lin, L.; Sinkov, S. I.; Law, J. D.; Modolo, G. An Advanced TALSPEAK Concept for Separating Minor Actinides. Part 1. Process Optimization and Flowsheet Development. Solvent Extr. Ion Exch., 2017, 35, 377-395.

[25] Wilden, A.; Lumetta, G. J.; Sadowski, F.; Schmidt, H.; Schneider, D.; Gerdes, M.; Law, J. D.; Geist, A.; Bosbach, D.; Modolo, G. An Advanced TALSPEAK Concept 
for Separating Minor Actinides. Part 2. Flowsheet Test with Actinide-Spiked Simulant. Solvent Extr. Ion Exch., 2017, 35, 396-407.

[26] Nilsson, M.; Nash, K. L. Review article: a review of the development and operational characteristics of the TALSPEAK process. Solvent Extr. Ion Exch., 2007, 25, 665701.

[27] Koma, Y.; Watanabe, M.; Nemoto, S.; Tanaka, Y. Trivalent lanthanide and actinide intra-group separation by solvent extraction with CMPO-complexant system. J. Nucl. Sci. Techn., 1998, 35, 130-136.

[28] Gelis, A.V.; Lumetta, G.J. Actinide Lanthanide Separation Process - ALSEP. Ind. Eng. Chem. Res., 2014, 53, 1624-1631.

[29] Wilden, A.; Modolo, G.; Schreinemachers, C.; Sadowski, F.; Lange, S.; Sypula, M.; Magnusson, D.; Geist, A.; Lewis, F. W.; Harwood, L. M.; Hudson, M. J. Direct Selective Extraction of Actinides (III) from PUREX Raffinate using a Mixture of $\mathrm{CyMe}_{4} \mathrm{BTBP}$ and TODGA as 1-cycle SANEX Solvent Part III: Demonstration of a Laboratory-scale Counter-Current Centrifugal Contactor Process. Solvent Extr. Ion Exch., 2013, 31, 519-537.

[30] Ansari, SA.; Pathak, P.; Mohapatra, PK.; Manchanda, VK. Chemistry of diglycolamides: promising extractant for actinide partitioning. Chem. Rev., 2012, 112, 1751-1772.

[31] Modolo, G.; Asp, H.; Schreinemachers, C.; Vijgen, H. Devolopment of a TODGA based process for partitioning of actinides from a PUREX raffinate part I: batch extraction optimization studies and stability tests. Solvent Extr. Ion Exch., 2007, 25, 703-721. 
[32] Modolo, G.; Asp, H.; Vijgen, H.; Malmbeck, R.; Magnusson, D.; Sorel, C. Demonstration of a TODGA-Based Continuous Counter-Current Extraction Process for the Partitioning of Actinides from a Simulated PUREX Raffinate, Part II: Centrifugal Contactor Runs. Solv. Extr. Ion Exch., 2008, 26, 62-76.

[33] Magnusson, D.; Christiansen, B.; Glatz, J.-P.; Malmbeck, R.; Modolo, G.; SerranoPurroy, D.; Sorel, C. Demonstration of a TODGA based extraction process for the partitioning of minor actinides from a PUREX raffinate. Part III: centrifugal contactor run using genuine fuel solution. Solvent Extr. Ion Exch., 2009, 27, 26-35.

[34] Bourg, S.; Hill, C.; Caravaca, C.; Rhodes, C.; Ekberg, C.; Taylor, R.; Geist, A.; Modolo, G.; Cassayre, L.; Malmbeck, R.; et al. ACSEPT - Partitioning technologies and actinide science: Towards pilot facilities in Europe. Nucl. Eng. Des., 2011, 241, $3427-3435$.

[35] Madic, C.; Hudson, M. J.; High-level liquid waste partitioning by means of completely incinerable extractants. EUR 18038 (Contract No. FI2W-CT91-0112), European Commission, Luxembourg, 1998.

[36] Lewis, F. W.; Harwood, L. M.; Hudson, M. J.; Geist, A.; Kozhevnikov, V. N.; Distler, P.; John, J. Hydrophilic sulfonated bis-1,2,4-triazine ligands are highly effective reagents for separating actinides(iii) from lanthanides(iii) via selective formation of aqueous actinide complexes. Chem. Sci., 2015, 6, 4812-4821.

[37] Geist, A.; Müllich, U.; Magnusson, D.; Kaden, P.; Modolo, G.; Wilden, A.; Zevaco, T. Actinide(III)/lanthanide(III) separation via selective aqueous complexation of actinides(III) using a hydrophilic 2,6-bis(1,2,4-triazin-3-yl)-pyridine in nitric acid. Solvent Extr. Ion Exch., 2012, 30, 433-444. 
[38] Ruff, C. M.; Müllich, U.; Geist, A.; Panak, P. J. Complexation of Cm(III) and Eu(III) with a hydrophilic 2,6-bis(1,2,4-triazin-3-yl)-pyridine studied by time-resolved laser fluorescence spectroscopy. Dalton Trans., 2012, 41, 14594-14602.

[39] Magnusson, D.; Geist, A.; Malmbeck, R.; Modolo, G.; Wilden, A.Flow-sheet design for an innovative SANEX process using TODGA and $\mathrm{SO}_{3}$-Ph-BTP. Proc. Chem., 2012, 7, 245-250.

[40] Modolo, G.; Wilden, A.; Kaufholz, P.; Bosbach, D.; Geist, A. Development and demonstration of innovative partitioning processes ( $i$-SANEX and 1-cycle SANEX) for actinide partitioning. Prog. Nucl. Energy, 2014, 72, 107-114.

[41] Wilden, A.; Modolo, G.; Kaufholz, P.; Sadowski, F.; Lange, S.; Sypula, M.; Magnusson, D.; Müllich, U.; Geist, A.; Bosbach, D. Laboratory-scale counter-current centrifugal contactor demonstration of an innovative SANEX process using a water soluble BTP. Solvent Extr. Ion Exch., 2015, 33, 91-108.

[42] Macerata, E.; Mossini, E.; Scaravaggi, S.; Mariani, M.; Mele, A.; Panzeri, W.; Boubals, N.; Berthon, L.; Charbonnel, M.-C.; Sansone, F.; Arduini, A.; Casnati, A. Hydrophilic Clicked 2,6-Bis-triazolyl-pyridines Endowed with High Actinide Selectivity and Radiochemical Stability: Toward a Closed Nuclear Fuel Cycle, J. Am. Chem. Soc., 2016, 138, 7232-7235.

[43] Wagner, C.; Mossini, E.; Macerata, E.; Mariani, M.; Arduini, A.; Casnati, A.; Geist, A.; Panak, P. J. Time-Resolved Laser Fluorescence Spectroscopy Study of the Coordination Chemistry of a Hydrophilic CHON [1,2,3-Triazol-4-yl]pyridine Ligand with $\mathrm{Cm}(\mathrm{III})$ and $\mathrm{Eu}(\mathrm{III})$. Inorg. Chem., 2017, 56, 2135-2144. 
[44] Kolarik, Z. Separation of actinides and long-lived fission products from high-level radioactive wastes (a review). KfK 4945, Kernforschungszentrum Karlsruhe GmbH, 1991.

[45] Sypula, M.; Wilden, A.; Schreinemachers, C.; Malmbeck, R.; Geist, A.; Taylor, R.; Modolo, G. Use of Polyaminocarboxylic Acids as Hydrophilic Masking Agents for Fission Products in Actinide Partitioning Processes. Solvent Extr. Ion Exch., 2012, 30, 748-764.

[46] Magnusson, D.; Geist, A.; Wilden, A.; Modolo, G. Direct Selective Extraction of Actinides(III) from PUREX Raffinate Using a Mixture of CyMe $\mathrm{C}_{4}$-BTBP and TODGA as 1-cycle SANEX Solvent PART II: Flowsheet Design for a Counter-Current Centrifugal Contactor Demonstration Process. Solvent Extr. Ion Exch., 2013, 31, 1-11.

[47] Sekine, T.; Hasegawa, Y. Solvent Extraction Chemistry: Fundamentals and Applications, Marcel Dekker Inc (Ed.), New York and Basel, 1977.

[48] Steczek, Ł.; Rejnis, M.; Narbutt, J.; Charbonnel, M.-C.; Moisy, P. On the stoichiometry and stability of americium(III) complexes with a hydrophilic $\mathrm{SO}_{3}-\mathrm{Ph}$ BTP ligand, studied by liquid-liquid extraction. J. Radioanal. Nucl. Chem., 2016, $306,891-897$.

[49] Kaufholz, P.; Modolo, G.; Wilden, A.; Sadowski, F.; Bosbach, D.; Wagner, C.; Geist, A.; Panak, P. J.; Lewis, F. W.; Harwood, L. M. Solvent Extraction and Fluorescence Spectroscopic Investigation of the Selective Am(III) Complexation with TS-BTPhen. Solvent Extr. Ion Exch., 2016, 34, 126-140.

[50] Lloyd, P. Principles of Industrial Solvent Extraction (Chapter 8). In Solvent extraction principles and practice, Marcel Dekker Inc (Ed.), 2002, 339-366. 
[51] Robin, T.; Mike, C.; Hitos, G.; Geist, A.; Hères, X.; Maher, C.; Mason, C.;

Malmbeck, R.; Miguirditchian, M.; Modolo, G.; et al. The EURO-GANEX Process:

Current Status of Flowsheet Development and Process Safety Studies. Proc. Chem., 2016, 21, 524-529.

[52] Magnusson, D.; Geist, A.; Malmbeck, R. SX process-A code for solvent extraction processes in centrifugal contactors simulation. Chem. Eng. Sci., 2013, 99, 292-297.

[53] D. Magnusson, Geist, A.; Malmbeck, R.; Müllich, U. Study of the Mass Transfer Behavior in a Centrifugal Contactor and Verification of the Solvent Extraction Model for the SX Process Program. Solvent Extr. Ion Exch., 2013, 31, 578-589. 